\title{
A SITUAÇÃO DA IMIGRAÇÃO NA ITÁLIA A PARTIR DAS CONTRIBUIÇÕES DO DOSSIÊ ESTATÍSTICO SOBRE IMIGRAÇÃO CARITAS/MIGRANTES
}

\author{
Marta Giuliani*
}

\section{Evolução e características da imigração na Itália}

Na Itália, como em outros países do sul da União Europeia, a imigração começou em meados dos anos 70, impulsionada por dois fatores: o esgotamento do impulso migratório interno e a adoção de novas políticas migratórias restritivas no norte da Europa. A imigração na Itália começou a se manifestar em um contexto caracterizado por uma evolução demográfica negativa, pela persistência do desemprego em grandes áreas do território nacional e pela necessidade de mão de obra adicional só em alguns setores produtivos (agricultura, serviços domésticos, construção civil, além de certos ramos industriais), normalmente sob a forma de emprego irregular. Enquanto no norte da Europa os fluxos anteriores foram suportar as grandes fábricas, isto não ocorreu no sul da Europa, onde os migrantes provenientes de vários continentes foram inseridos principalmente em setores, como a agricultura, ainda caracterizados por um elevado desemprego, ou nos setores dos serviços de alta demanda em áreas urbanas. No caso italiano, é preciso também levar em conta a localização geográfica da Península, com fronteiras muito extensas, ubicada em uma área com forte pressão migratória na confluência dos continentes africano e asiático, além das fronteiras da Europa Oriental.

\footnotetext{
Licenciada em Estudos Latino-americanos com especialização em Antropologia Cultural pela Universidade de Londres, Mestre em Migrações Internacionais e Relações Interculturais pelo Scalabrini International Migration Institute de Roma. Atualmente é editor do Dossiê Estatístico sobre Imigração Caritas/Migrantes e membro do Ponto de Contato Nacional para a Rede Europeia das Migrações EMN (European Migration Network). E-mail: marta.giuliani@emnitaly.it. Roma/Italia.
} 
Nos anos 70 e 80 a imigração na Itália foi um fenômeno incipiente e de proporções contidas. Os primeiros fluxos foram compostos prevalentemente por trabalhadoras domésticas, com baixa visibilidade social, e solicitantes de asilo político, muitas vezes em trânsito para outros países. Entre os italianos continuava a prevalecer a atenção para as comunidades de compatriotas no exterior e não se pensava na possibilidade que a Itália se tornasse um país de imigração. Não é por acaso que ainda se aplicavam as regras de segurança pública estabelecidas em 1931 (Decreto Real de 18 de junho de 1931, n. 773), quando a Itália era uma realidade radicalmente monocultural.

Desde 1986, ano da primeira lei nacional sobre a imigração, e por quase todos os anos 90, desenvolveu-se uma fase que poderia ser chamada de "emergência", em que o país foi forçado a enfrentar um fenômeno que começava a assumir uma dimensão quantitativamente significativa. Para os migrantes a Itália se tornava cada vez mais um país de "primeira escolha", sobretudo após a queda do Muro de Berlim e o início da imigração proveniente da Europa Oriental. No entanto, faltava no país uma visão a médio e longo prazo, bem como a consciência das implicações estruturais da imigração, o que gerou importantes consequências na questão legislativa.

Em 1989, o assassinato, no povoado de Villa Literno, do cidadão Sul Africano Jerry Essan Masslo induziu um vasto movimento de opinião pública a se manifestar contra a intolerância de fundo racial e promoveu a promulgação da Lei de 1990 (a chamada Lei Martelli). Nos anos 90 abriuse uma fase de reflexão sobre o fenômeno da imigração que, depois de um caminho conturbado, levou à aprovação da primeira lei abrangente sobre a imigração (1998).

Na primeira década de 2000 as intervenções legislativas (2002 e 2009) se caracterizaram por sua natureza restritiva, redimensionando a abertura da Lei de 1998, mas sem revogá-la: uma tendência ainda perceptível nas atuais disposições legais.

Do ponto de vista quantitativo, desde 1970 ao início de 2011, os imigrantes na Itália aumentaram 35 vezes e, de uma presença marginal, tornaram-se um dos fenômenos sociais mais relevantes no atual contexto nacional. Com um ritmo médio anual de crescimento que não tem igual em outros países industrializados (se não na Espanha), no entanto, a Itália ainda tem dificuldade para desenvolver uma visão e uma consciência comum dos aspectos estruturais do fenômeno migratório. No entanto, mesmo em termos de visibilidade, passou-se de uma incidência de 1\% de cidadãos estrangeiros, no início dos anos 90 do século passado, para 7\%, a partir de 2009, uma tendência que colocou a Itália acima da média Europeia (que no mesmo ano 
foi $6,5 \%)$, acima da França (5,8\%), ao mesmo nível que o Reino Unido $(7,0 \%)$ e apenas depois da Alemanha (8,7\%) e da Espanha (12,3\%).

Entre os 5 milhões de estrangeiros regularmente presentes, foram 3 milhões aqueles registrados só nos últimos três anos. Isto não surpreende, sobretudo em se considerando que, no período entre 2000-2010, na Itália o aumento das pessoas com mais de 65 anos (1,8 milhões) foi bem maior em relação ao aumento da população em idade ativa (1.456.000) e das crianças até 14 anos (348.000); em relação a este processo de envelhecimento, a imigração constitui um importante remédio, ainda que parcial. De fato, os estrangeiros na Itália, cuja idade média é de 32 anos (contra os 44 dos italianos), são caracterizados pela forte incidência de menores $(21,7 \%)$ e de pessoas em idade ativa (78,8\%), enquanto as pessoas maiores de 65 anos são apenas 2,3\% (contra 20,3\% entre a população total). É cidadão estrangeiro 1 a cada 100 idosos e 1 a cada 10 menores ou jovens adultos (18-39 anos). Além disso a taxa de fertilidade (ou seja o número de filhos por cada mulher de 15 a 44 anos) é de 1,29 entre as italianas e de 2,13 entre as estrangeiras, enquanto cerca de 1/7 (14\%, 78.082) dos nascidos na Itália em 2010 é filho de pais ambos estrangeiros (una quota que chega a 18,4\% considerando também os nascidos de mãe estrangeira e pai italiano).

Diante de tudo isso, os imigrantes representam um autêntico "amortecedor" demográfico, ainda mais em se considerando que o Istat (Instituto Nacional de Estatística) calcula que, na Itália, entre 2005 e 2020, vão faltar 4,5 milhões de jovens entre os 19 e os 44 anos, ou seja, em média 300 mil ao ano por todo o período em análise. Por outro lado, o déficit demográfico se reflete também na força de trabalho, o que explica porque as empresas e as famílias italianas, não achando mão de obra nacional, recorram aos trabalhadores estrangeiros.

As regiões nacionais que exercem maior poder de atração sobre a população imigrada são o Noroeste, que inclui mais de um terço da presença estrangeira na Itália $(35,0 \%)$, o Nordeste $(26,3 \%)$ e o Centro $(25,2 \%)$; muito atrás na classificação colocam-se o Sul $(9,6 \%)$ e as Ilhas (3,9\%).

O Norte desenvolve uma função de "ímã" por oferecer importantes oportunidades de trabalho (especialmente na região Lombardia, cuja capital é Milão). O Centro, que no passado foi a região de maior imigração, continua a exercer uma forte atração pela oferta de empregos nos setores de serviços, especialmente na área da cidade de Roma, e nos setores produtivos da indústria da Toscana. 
O Sul e as Ilhas da Sardegna e da Sicília acolhem menos que um sexto de toda a presença da imigração na Itália e representam, na maior parte das vezes, um ponto de apoio para outras destinações, seja porque muitos imigrantes deixam esta região para seguir outros projetos migratórios, seja porque um expressivo número de imigrantes que conseguem chegar à costa da Sicília sem autorização são repatriados.

Os dois maiores pólos da imigração são a Lombardia e o Lazio. A Lombardia é a primeira região em número de residentes estrangeiros (1.064.447, com uma incidência de 10,7\% sobre a população total), e Milão a primeira província (382.490 estrangeiros, com uma incidência de 12,1\%), seguida da região do Lazio (542,688 residentes estrangeiros, 9,5\%), na qual se destaca a província de Roma (442,818 residentes estrangeiros, 10,6\%). No último lugar da classificação encontra-se a Ilha da Sardenha, com aproximadamente um estrangeiro a cada 50 residentes (incidência média de 2,3\%). Seja como for, a imigração adquiriu una forte visibilidade em todo território, com uma vasta variedade de nacionalidades, línguas, culturas e tradições.

\section{O cenário atual: fluxos e principais comunidades}

Os estrangeiros residentes na Itália eram pouco mais de 100.000 em 1951, mas no início de 2011 esse número chegou a 4.570.317, dos quais 51,8\% mulheres. No total da população residente na Itália (60.626.442), a incidência dos estrangeiros é de 7,5\%. O aumento anual, apesar da crise, foi de 335.258 unidades, devido principalmente aos novos inscritos nos Cartórios de estado civil (Anagrafe) provenientes do exterior $(+424.499)$ e, em segundo lugar, por causa das crianças estrangeiras nascidas na Itália (78.082 em 2010). Entre os excluídos das listas de residentes encontram-se 32.817 imigrantes transferidos para o exterior e cerca de 5 mil estrangeiros falecidos, enquanto houve cerca de 91 mil cancelamentos nos Cartórios por destinação desconhecida e vencimento da autorização de residência. Além disso, precisa levar em conta que a cada ano cresce o número de migrantes que adquiriram a cidadania italiana. Junto aos residentes, de acordo com a estimativa do Dossiê Estatístico sobre Imigração Caritas/Migrantes, deve-se acrescentar mais de 400 mil pessoas presentes regularmente, mas ainda não registradas no Cartório de Registro.

Quanto aos países de origem dos imigrantes residentes na Itália há uma significativa variedade, revelando uma proveniência heterogênea e representativa de quase o mundo inteiro, o que leva a falar do caráter policêntrico da imigração na Itália. A comunidade mais numerosa é a romena, que alcança cerca 1 milhão de residentes (968.576), seguida da albanesa e da marroquina, ambas com quase meio milhão (respectivamente 482.627 
e 452.424), enquanto os chineses e os ucranianos são aproximadamente 200.000 (209.234 e 200.730). No total essas cinco comunidades cobrem mais da metade da presença dos imigrantes na Itália (50,6\%), assim como ocorre com os europeus na sua totalidade $(53,4 \%)$.

Em conformidade com as tendências registradas nos últimos anos, permanece, portanto, o protagonismo dos países do Leste Europeu, principal área de origem dos fluxos imigratórios no país a partir da regularização de 2002, com um ápice em 2007 quando, em consequência da entrada da Romênia e da Bulgária na União Europeia, a área chegou a cobrir mais de três quartos $(77 \%)$ do incremento registrado no decorrer do ano.

Relevante e equivalente a quase um quarto do total $(23,6 \%, 79.147)$ é a quota do incremento proporcionado pelo continente asiático, uma área geográfica que mostra uma progressiva intensificação dos fluxos em direção à Itália (totalizando 20,7\% do aumento registrado no ano de 2009, equivalente a 71.305 pessoas). Trata-se de imigrantes oriundos principalmente do centrosul do continente $(12,3 \%)$.

Os cidadãos de países africanos, provenientes sobretudo do Norte da África $(9,6 \%)$, são responsáveis pelo aumento da população de estrangeiros inscritos no registro civil de quase um sexto (16,3\%, 54.678 pessoas), enquanto, com um crescimento de quase 30 mil residentes, os cidadãos latinoamericanos participam com um incremento total de doze avos (29.242, 8,7\%), devido sobretudo aos fluxos migratórios da América Central e da América do Sul, principalmente do Peru (10.856, 3,2\%).

A evolução dos fluxos de imigração na Itália, ou melhor, o progressivo aumento de residentes estrangeiros, permanece fortemente condicionado pelas leis em matéria, principalmente no caso de cidadãos não comunitários, cujo ingresso com visto de trabalho no país é rigorosamente controlado através das normas que estabelecem quotas de ingresso a cada ano, repartidas também com base na nacionalidade dos aspirantes à imigração, sendo que algumas quotas restam reservadas aos cidadãos de países que assinaram acordos bilaterais com a Itália. Ao mesmo tempo, ao avaliar o progressivo aumento de residentes estrangeiros, não se podem ignorar os efeitos dos procedimentos de regularização, um instrumento do qual a política italiana em matéria de imigração fez largo uso, demonstrando a ineficiência das medidas de gestão do fenômeno até então adotadas: podem-se contar seis regularizações entre 1986 e 2009 (1986, 1990, 1995, 1998, 2002 e 2009) e só nos anos 90 mais de $60 \%$ do aumento da população estrangeira foi provocado por estes procedimentos. 
A diferença entre estes dois instrumentos (quotas e regularizações), quanto aos seus efeitos na representação estatística dos fluxos através dos registros civis, é clara. Por um lado, há um instrumento como as quotas que condiciona o volume e a subdivisão por comunidades dos ingressos regulares e, portanto, das inscrições civis do exterior (principal componente do incremento dos cidadãos estrangeiros residentes); por outro lado, há uma medida excepcional que dá visibilidade jurídica e laboral (e, portanto, estatística) aos não-comunitários irregularmente presentes no país, na maior parte das vezes chegados à Itália apesar das restrições impostas pelos "decretos fluxos" e também dos vínculos que regulam o ingresso na Itália por razões diversas do trabalho. E, por outro lado, na maior parte das vezes, os "decretos fluxos" funcionam como "regularizações mascaradas", que de fato permitem a visibilidade dos trabalhadores migrantes já presentes no país. Os dados sobre os estrangeiros residentes, portanto, refletem as tendências dos fluxos migratórios, mas o fazem através do filtro da legislação sobre a imigração que inevitavelmente afeta o seu andamento. E desses condicionamentos tem que se levar em conta na avaliação do aumento da população estrangeira residente, sobretudo em se considerando a composição por nacionalidade. De qualquer modo, enquadrados em um longo período, os dados descrevem claramente as modificações que atravessaram o panorama da imigração na Itália no decorrer dos últimos anos.

A composição por gênero, em consequência dos diferentes modelos migratórios de referência, varia consideravelmente de acordo com o grupo nacional. Portanto, se no complexo da presença imigrante a relação de gênero é substancialmente equilibrada, com as mulheres que superam levemente a presença dos homens (com 51,8\%), a avaliação por comunidades traz a tona uma ampla diversificação. A comunidade com maior presença feminina é a da Ucrânia, com 79,8\%, enquanto aquela com maior presença masculina do Senegal, com $75,6 \%$. Em um panorama geral, as mulheres prevalecem nas comunidades europeias e, ainda que em maneira menos acentuada, nas comunidades latinoamericanas, enquanto os homens representam o grupo majoritário entre os migrantes do norte da África, África Ocidental e Centro-Sul da Ásia.

\section{Internacionalização do mercado de trabalho}

No período 2000-2009 na Itália a produtividade cresceu somente 1,4\%, contra o 10,0\% dos países da zona euro e o 12,7\% dos 27 países da UE. Relevante no período 2008-2009 foi a diminuição de 6,5 pontos percentuais do PIB, uma redução que continuou em 2010, quando houve um forte declínio no mercado de trabalho, o que trouxe como consequência 
nos três anos seguintes a perda de 800 mil empregos. Atualmente, mais de um quarto dos jovens trabalhadores é desempregado e são 2 milhões os jovens sem perspectiva, que não estudam nem procuram trabalho.

Nesse cenário negativo, os imigrantes tiveram grande importância. No mercado de trabalho italiano a internacionalização começou há muito tempo atrás: atualmente os imigrantes constituem um décimo da força de trabalho (2.089.000, segundo o Instituto Nacional de Estatística, e cerca 200 mil a mais incluindo os não-residentes) e tal importância é determinante em diversos setores produtivos. Grandes protagonistas do mercado de trabalho são também as mulheres, que representaram mais da metade dos novos empregos em 2010, embora sejam sujeitas a discriminação nas possibilidades de conjugar família e trabalho. São mais de 1 milhão as mulheres imigrantes que prestam serviços de assistência a idosos e crianças, e na metade dos casos sem proteção previdenciária e Seguro Acidente de trabalho. Setores com altas concentrações de imigrantes são também a construção civil e a agricultura, mas a presença migrante se estende em maneira homogênea, tanto é que, na última década, o crescimento da ocupação foi devido quase unicamente à inclusão laboral dos imigrantes recém-chegados.

Os trabalhadores estrangeiros possuem uma elevada taxa de atividade (71,4\% vs $61,4 \%$ dos italianos), devido a uma maior disponibilidade de realizar trabalhos frequentemente desprezados pelos italianos, inclusive em tempos de crise. Os imigrantes, portanto, desempenham um papel complementar. Além disso, os trabalhadores estrangeiros são expostos a maiores condições de risco (em 2010 foram registrados 120.135 acidentes no trabalho, dos quais 138 fatais), encontram dificuldades no reconhecimento de títulos de estudo e qualificações, são inseridos em trabalhos mais pesados e recebem retribuições inferiores. É bom lembrar também que não afetou positivamente o fato de que, na primeira década de 2000, cerca de um milhão de estrangeiros ingressou no mercado de trabalho informal - como evidenciado pelas regularizações de 2002 e 2009: esta exclusão inicial do mercado de trabalho regular prejudicou a tutela dos direitos fundamentais.

Diante dos efeitos da crise, temos que ressaltar que os imigrantes, que contribuem ao produto interno bruto por mais de $11 \%$, representam antes uma solução do problema do que a causa do mesmo. Vários estudos evidenciaram a função complementar dos trabalhadores imigrantes, capazes de facilitar a melhoria das oportunidades de emprego dos próprios italianos. Se a força de trabalho estrangeira deixar de aumentar, os setores produtivos que não atraem mais os italianos (agricultura, construção, assistência familiar e outros serviços) ficarão em sérias dificuldades. 
Além disso, nas últimas pesquisas realizadas sobre benefícios e custos da imigração, o Dossiê Estatístico sobre Imigração 2011 evidenciou que os imigrantes trazem aos cofres públicos mais do que utilizam como beneficiários das prestações e serviços sociais. A relação entre o gasto público utilizado em favor dos imigrantes (10,5 bilhões de euros) e os impostos arrecadados pelos estrangeiros (12 milhões) resulta, portanto, em favor do Estado italiano.

Outro aspecto positivo do fenômeno migratório está na questão da Previdência Social, já que os estrangeiros garantem uma renda previdenciária consistente (mais de 7 bilhões ao ano) sem receber o correspondente em prestações de serviços públicos, o que permitiu equilibrar o orçamento previdenciário. Tendo por base a idade da aposentadoria, pode-se prever que no quinquênio 2011-2015 vão se aposentar um total de 110.000 estrangeiros, ou seja $3,1 \%$ de todos os novos pedidos de aposentadoria. Das 15.000 aposentadorias de 2010, equivalentes a 2,2\% de todas as novas solicitações, se passará às 61.000 em 2025, correspondentes a 7\% dos ingressos. Atualmente, entre os imigrantes os aposentados representam 1 a cada 30 residentes, enquanto entre os italianos 1 a cada 4. Em 2025, os aposentados estrangeiros serão no total $625 \mathrm{mil}$ (8\% dos residentes estrangeiros). Em tal data, entre os cidadãos estrangeiros só haverá 1 aposentado a cada 12, enquanto entre os italianos a relação será de 1 a cada 3 .

Atualmente, porém, os imigrantes estão pagando duramente os efeitos da crise, chegando a representar um quinto dos desempregados. Nesta ótica gera perplexidade a extrema precariedade das autorizações de permanência no território nacional, que são concedidas por motivos que dizem respeito a um contexto de estabilidade. O elevado número de autorizações não renovadas no vencimento (cujo total ultrapassa as 200.000 unidades) induz a refletir sobre a oportunidade de modificar as normas atuais, já que o perdurar da situação do desemprego acaba afetando a renovação das autorizações de permanência, forçando os estrangeiros à repatriação ou à irregularidade.

\section{O protagonismo empresarial}

A liberalização do acesso ao trabalho autônomo aos imigrantes foi estabelecida pela Lei 40/1998. Daí em diante desenvolveram-se massivamente as iniciativas empreenditoriais. Entre os imigrantes ocupados, aproximadamente 1 a cada 10 desenvolve um trabalho de caráter empresarial. Os cidadãos estrangeiros que detêm uma posição empreenditorial (titulares, administradores, parceiros, etc.), em 31 de dezembro de 2010, foram 415.394, enquanto em 2005 eram somente 300.000, com um aumento de 40,4 pontos percentuais (entre os italianos houve uma diminuição de 9,1\%). Entre estes, os 
titulares de empresas são atualmente 228.540 (19.712 a mais em relação ao ano precedente), com quatro comunidades que detêm uma quota superior a 10\%: Marrocos 16,4\%, Romênia 15,3\%, China 14,7\% e Albânia 10,4\%. Cabe lembrar também que $72,2 \%$ das empresas dirigidas por estrangeiros operam no setor da construção civil $(37,4 \%)$, do comércio e manutenção $(34,8 \%)$. Trata-se de setores nos quais não é necessário um elevado capital inicial e que não são caracterizados por um alto nível tecnológico. Os empresários imigrantes estão sub-representados na agricultura, devido à necessidade de dispor de um capital conspícuo para adquirir terras.

Entretanto, o crescimento dos empresários estrangeiros, apesar dos ritmos elevados, foi prejudicado pela crise econômica. Se até 2007 houve um aumento a uma taxa média anual de vinte pontos percentuais, depois se assistiu a uma redução drástica nas taxas de expansão que, de fato, resultam ser quase a metade em relação aos anos anteriores à crise.

As empresas dos imigrantes são de pequenas dimensões e muitas vezes constituídas só pelo titular. O fenômeno de titulares de empresas estrangeiros porém, se considerado no seu total, merece uma atenta consideração por seu contínuo crescimento, apesar das maiores dificuldades encontradas pelos imigrantes em relação aos italianos, como por exemplo na obtenção das autorizações e, sobretudo, dos créditos necessários. Entre os titulares e outras figuras empresariais, tais como parceiros e trabalhadores dependentes, estimase que haja mais de meio milhão de pessoas.

Apesar do uso recorrente do termo "empreendedorismo étnico", essas empresas oferecem serviços não somente ao seu próprio grupo nacional, mas também ao mercado na sua totalidade, cultivando uma clientela predominantemente italiana. As formas de auto-emprego são muito diversificadas e, enquanto alguns repropõem atividades já exercidas nos países de origem, para outros trata-se de uma escolha inovadora devido ao espírito de iniciativa amadurecido no contexto italiano. Para muitos o empreendedorismo foi uma maneira de livrar-se dos preconceitos com os quais são enquadrados, mostrando capacidade de realizações significativas e conseguindo também remunerações maiores em comparação com os baixos salários geralmente reservados aos trabalhadores subordinados estrangeiros.

Os principais setores de trabalho são a construção civil e o comércio. Evitando cair em generalizações e estereótipos, pode-se todavia constatar que os norte-africanos são majoritários nos setores do comércio e da gastronomia, os chineses nas empresas comerciais e em alguns ramos da indústria transformadora (têxtil, couro), os bengaleses e os paquistaneses no comércio ambulante e nas pequenas atividades comerciais a retalho. 
A experiência italiana induz a ressaltar que o empreendedorismo é sem dúvida um caminho válido para a inserção e está permitindo, por vezes, a sobrevivência de vários ofícios artesanais funcionais ao bem-estar da população. Por outro lado, o empreendedorismo pode ser funcional não só às necessidades dos compatriotas estabelecidos na Itália, mas também às necessidades dos países de origem, dando a possibilidade de iniciar projetos locais de produção, comercialização e crédito e de ativar um maior fluxo comercial, inclusive através de uma utilização mais efetiva das remessas.

\section{O processo de inserção estrutural na sociedade: menores, famílias e matrimônios mistos}

A inserção dos imigrantes, além de ser evidenciada por um forte aumento numérico, tornou-se sempre mais sólida. Essa presença transformouse cada vez mais em um fenômeno estável e familiar, como atestam diversos indicadores: a equiparação quantitativa entre homens e mulheres, a prevalência dos casados em relação aos solteiros, a convivência com membros do próprio núcleo de origem, o aumento de filhos de imigrantes nascidos na Itália (cerca de 80.000 por ano).

Esta evolução foi sem dúvida influenciada pela progressiva feminização da migração: no início dos anos 90 as mulheres imigrantes representavam apenas $40 \%$ da população imigrante no total; atualmente são substancialmente equiparadas aos homens em nível nacional, enquanto em algumas comunidades, em diferentes regiões e em muitas províncias (especialmente no Norte e no Centro-sul da Itália), constituem uma clara maioria. De forma específica, são mais ou menos quarenta os grupos nacionais nos quais a incidência das mulheres supera $70 \%$ do total; menos numerosos são aqueles nos quais a porcentagem é superior a 80\%, como, por exemplo, a Ucrânia.

Os filhos de estrangeiros menores de idade são quase 1 milhão e aumentam de mais de 100 mil unidades por ano, entre nascidos no território italiano e crianças chegadas na Itália pela reunificação familiar. A incidência dos menores em relação aos estrangeiros residentes supera 23\% no Nordeste da Itália e diminui para 17\% no Sul, com diferenças consideráveis também em relação a cada comunidade.

Esses menores, em mais da metade dos casos, concentram-se na faixa de idade do ensino obrigatório (6-16 anos). No entanto é significativo que mais de 4 crianças a cada 10 são menores de 6 anos (entre os italianos a porcentagem é quase a metade) e que cerca 6 a cada 10 são nascidas na Itália, o que demonstra a elevada taxa de fertilidade dos migrantes. 
Em 2010 as aquisições da cidadania registradas pelo Ministério do Interior foram 40.223, às quais vão adicionados os 26.000 casos de reconhecimento da cidadania sob a jurisdição do registro municipal, relativos principalmente aos estrangeiros nascidos na Itália que se tornaram maiores de idade. No seu complexo, estima-se que na Itália residam mais de 600.000 italianos por naturalização, um número significativo, mas inferior às aquisições da cidadania registradas na União Europeia em um único ano (776.000 em 2009).

É crescente o número de aquisições de cidadania por casamento (21.630). Os matrimônios celebrados na Itália no seu total diminuíram de 418.494, em 1972, para pouco mais de 217.000, em 2010, com uma redução especialmente dos primeiros casamentos, um aumento dos segundos casamentos (um sexto do total) e da idade média dos esposos (30 anos para as mulheres e 33 anos para os homens). Nas últimas décadas, os modelos familiares italianos incorporaram sempre mais insistentemente as mudanças determinadas pelos processos imigratórios, acolhendo novas e diversificadas expressões culturais e relacionais, seja na forma das uniões entre estrangeiros, seja nos casamentos mistos. Foram 257.762 os matrimônios mistos entre 1996 e 2009, ano no qual aos 21.357 casamentos mistos ( 1 a cada 10 celebrados) adicionaram-se 10.702 casamentos com ambos os esposos estrangeiros. Em 1995 eram mistos somente dois casamentos a cada 100, enquanto agora são quase 10 a cada 100.

Os filhos de imigrantes inscritos na escola no ano letivo 2010/2011 foram 709.826 e incidiram em 7,9\% da população escolar. Os dados revelam um atraso escolar três vezes maior do que o registrado entre os italianos, sublinhando a necessidade de empregar mais recursos para a sua inclusão no caso dos meninos imigrados por via da reunificação familiar. Mais de metade dos menores são migrantes de segunda geração, ou seja, crianças e jovens nascidos na Itália, para os quais o adjetivo "estrangeiro" é totalmente inadequado, pois são iguais aos italianos por lugar de nascimento, residência, idioma, sistema formativo e percurso de socialização. A segunda geração superou as 600 mil unidades e representa mais de um décimo da população estrangeira residente. A falta de acesso à cidadania representa um fator de exclusão de enorme relevância. Diferentes investigações revelaram que os italianos seriam propensos à concessão de cidadania em condições mais favoráveis às crianças estrangeiras nascidas na Itália, mas essa perspectiva ainda não encontrou um aval em nível legislativo.

\section{Os cenários futuros}

Ha muito tempo, a população italiana é caracterizada pela prevalência de falecimentos sobre os nascimentos e por um consistente envelhecimento. 
A quota dos jovens trabalhadores entre 18 e 44 anos, segundo as projeções do Istat, entre 2005 e 2020 diminuirá de 4 milhões e meio de unidades. A miragem de uma "imigração zero" é uma hipótese completamente irreal e, de acordo com o Eurostat, em meio século causaria na Itália a perda de um sexto da sua população.

O ingresso anual de 240.000 estrangeiros, previsto nas últimas projeções demográficas do Istat como cenário alto, deve ser considerado como aquele com maior credibilidade de acordo com as tendências observadas nos últimos anos. Realisticamente, pode-se supor que a Itália superará a Alemanha como primeiro país de imigração entre 2020, enquanto em 2050 o número previsto de cidadãos estrangeiros será de 12,3 milhões, igual a 18\% da população.

Diante dessas exigências demográficas e ocupacionais, os fluxos necessitam, naturalmente, de uma regulamentação adequada, mas seria errado não insistir na integração de uma presença que, ao que tudo indica, continuará a aumentar nos próximos anos; seria extremamente míope valorizar somente as normas de contraste, necessárias mas de eficácia limitada, de custo excessivo e sujeitas a imprevistos, como constatou-se em ocasião dos eventos do Norte da África no primeiro semestre de 2011.

A respeito das previsões demográficas, é preciso sintetizar um comentário do conhecido demógrafo Antonio Golini, publicado no Dossiê Estatístico sobre Imigração Caritas/Migrantes 2008. A imigração estrangeira, com fluxos intensos e abrangentes até há pouco inimagináveis, transforma e continuará transformando a estrutura e as tendências da população residente na Itália, considerando que os cidadãos de origem italiana vão experimentando há mais de três décadas uma fertilidade excepcionalmente baixa, para a qual não havia precedentes na história da humanidade quanto ao nível e à duração.

A imigração estrangeira, que se estabilizará de maior forma nas regiões mais ricas do Centro-Norte (onde a população se tornará, assim, comparativamente menos idosa), deve ser considerada um elemento estrutural e central da população italiana e não mais um elemento marginal e marginalizado como foi entendido e colocado até agora. Estamos diante de uma verdadeira revolução, que requer políticas muito mais ativas das atuais em matéria de integração, com particular referência ao trabalho, à casa, à escola, à saúde e à mobilidade social, componentes essenciais para um adequado e apropriado crescimento das segundas gerações e, portanto, para uma duradoura e benéfica paz social.

O envelhecimento da população italiana continuará de maneira intensa, apenas levemente afetado pela contribuição positiva da imigração, seja com o 
aumento até o nível de 33\% dos maiores de 60 anos (contra o atual 20\%), seja com a diminuição até o nível de 12,8\% (contra o atual 14,1\%) das pessoas com menos de 15 anos. A população em idade ativa diminuirá, apesar da imigração estrangeira, de cerca de 1,1 milhão de pessoas na região do Centro-Norte e de cerca de 4,5 milhões no Sul. Esta mudança demográfica não poderá deixar de influir na riqueza produzida nessas áreas.

Os países economicamente desenvolvidos, pelo previsto declínio na população em idade laboral, terão a necessidade de imigrantes, enquanto naqueles em via de desenvolvimento a população em idade ativa aumentará de quase 1,7 bilhões de pessoas. A pressão migratória Sul-Norte será portanto muito forte e incontrolável. De forma específica, a África, na segunda metade do século, atingirá dois bilhões de habitantes e os africanos na Itália, que agora são pouco menos de 1 milhão, após a explosão demográfica de seu continente poderão alcançar 3 milhões. A possibilidade e a capacidade de criar empregos suficientes e trabalhos decentes para lidar com uma oferta de mão de obra que nas próximas décadas superará largamente 1 bilhão e meio de pessoas, constitui um dos desafios principais para a humanidade, desafio que, com toda a evidência, pode interferir com as projeções italianas e europeias em geral.

\section{Algumas observações conclusivas}

Os dados estatísticos coletados no Dossiê constituem um fio condutor das reflexões sobre a imigração. Embora tornou-se um grande país de imigração na União Europeia, a Itália demora a metabolizar esta mudança estrutural sem a qual, desde os anos 90, teria experimentado o declínio da população, do emprego e do PIB.

A Itália tornou-se estruturalmente um país multicultural; também como consequência das exigências demográficas e ocupacionais acima citadas, estabeleceram-se em maneira estável comunidades oriundas de diferentes partes do mundo. A dimensão multicultural é uma constatação de fato, enquanto a interação, a coesão e a perspectiva intercultural são um objetivo a alcançar. O caminho traçado pela história vai no sentido da integração, como atestam vários indicadores: a crescente presença e incidência dos cidadãos estrangeiros, do número de menores e dos novos nascimentos, da frequência escolar, das segundas gerações, dos casamentos mistos e das aquisições de cidadania.

Diante do perfil institucional, no mês de junho de 2010 foi divulgado e considerado positivamente o plano inter-ministerial pela integração denominado "Identidade e encontro", no qual é proposto um programa pela integração na 
segurança, qualificado como modelo italiano de integração, longe da assimilação e do multiculturalismo. No documento são identificados caminhos focalizados nos direitos e deveres, nas responsabilidades e oportunidades, em uma visão de relação recíproca que tem por base as pessoas e as iniciativas sociais mais que o Estado, identificando cinco áreas de ação: educação e aprendizagem, língua e valores, trabalho e formação profissional, moradia e governança local, acesso aos serviços essenciais, atenção aos menores e às segundas gerações. Nesse documento governamental insiste-se, assim como acontece em âmbito comunitário, na migração de caráter rotatório, nos retornos e no apoio ao desenvolvimento, gradualmente reduzido a um nível mínimo. Enraizou-se, portanto, a convicção, apoiada pelos dados, que a imigração esteja adquirindo um caráter cada vez mais estável.

De fato, somente depois que ao cidadão estrangeiro será reconhecida a igualdade de oportunidades em termos de casa, trabalho, saúde, educação e participação política, serão colocadas as bases efetivas para uma inclusão decente, superando o modelo de integração subalterna, do tipo funcionalutilitário, que canaliza os migrantes em direção a determinados setores reservando a eles funções menos gratificantes.

\section{Referências bibliográficas}

CARITAS/MIGRANTES. Dossier Statistico Immigrazione 2011: XXI Rapporto. Roma: Idos, 2011.

. Dossier Statistico Immigrazione 2010: XX Rapporto. Roma: Idos, 2010.

CENSIS. Rapporto sulla situazione sociale del Paese 2011. Milano: Franco Angeli, 2011.

CNEL. Indici di integrazione degli immigrati in Italia: Ottavo Rapporto. Roma: Cnel/ Onc, 2012. Disponível em: www.cnel.it. Acesso em: 03/09/2012.

EMN ITALY. Immigrants and refugees: Legislation, institutions and competences. Fifth EMN Italy Report. Rome: Idos, 2012.

. Migration channels: Visas and irregular flows. Fourth EMN Italy Report. Rome: Idos, 2012.

INPS - DOSSIER STATISTICO IMMIGRAZIONE CARITAS/MIGRANTES. IV Rapporto sui lavoratori immigrati negli archivi Inps. Roma: Idos, 2011.

IOM. 1951-2011: Migration in Italy between past and future. Rome: Idos, 2012.

MINISTERO del Lavoro e delle Politiche Sociali - Direzione Generale dell'Immigrazione. Comunicare l'immigrazione: Guida pratica per gli operatori dell'informazione. Bologna: Lai Momo - Idos, 2012. 